\title{
Advantages of using both bathymetry and laser scanning technology for virtual inspection of water retention infrastructure and hydraulic modelling
}

\author{
T. Mitchell \\ Fugro Consultants, Inc., USA
}

\begin{abstract}
Recent integration of bathymetric underwater surveying technology with mobile laser scanning from the same vessel platform allows engineers, operators and maintenance personnel in several disciplines the opportunity to inspect water retention features (such as dams and levees) in a virtual desktop environment. The nature of the data collected along the watercourse characterizes the river both above and below the waterline at any location. Additionally, it allows consideration of the impact of objects affecting river flow during hydraulic modelling as well as evaluation of changes in the river caused by sediment dynamics. The product is a comprehensive data set that extends from the riverbed, through the riparian zone and into the floodplain and captures features with an unprecedented degree of resolution and detail. Consequentially, virtual inspection and assessment of assets and features as well as improved detail and accuracy in hydraulic modelling become possible. The result is a major improvement in the ability of an individual to perform an evaluation of the watercourse.
\end{abstract}

Keywords: surveying, bathymetry, LiDAR, laser scanning, virtual inspection hydrologic modelling.

\section{Introduction}

Water retention infrastructure plays a vital role in protecting communities from the dangers of flood hazards and in many cases provides sources for hydroelectricity. Episodic events that jeopardize this infrastructure as well as 
decay and wear over time put lives and property at risk requiring that these infrastructure features be monitored for susceptibility to failure. In addition, many dams and levees have been constructed without adequate engineering during design, not built to the design criteria and/or do not have proper characterization of the geomorphology and as such have a heightened risk of failure.

Adequate characterization of the state of dams and levees has become of critical importance. Yet the enormous extent of the infrastructure that requires evaluation makes this a formidable challenge to those with this responsibility. The opportunity to rapidly survey this infrastructure and virtually inspect it is valuable.

Further, data of this nature can also play a role in modeling watercourse hydraulics both in one and two dimensions. A data set spanning both sides of the waterline allows engineers to produce cross sections at nearly any interval for finite difference models as well as to allow for producing cross sections at different angles if the model requires changing the position of the river centerline. Similarly, the same data set can be used to populate elevation values in a triangulated mesh of high complexity and varying density for finite element modeling.

\section{Technology}

Providing topographic data both above and below the water line is challenging. Airborne Laser Bathymetry (ALB) technology has been shown to be effective (Axelsson and Alfredsson [1] and Banic and Cunningham [2]) but is typically very costly for small projects. Sensors are also limited in availability since so few have been made and the costs to manufacture and operate are high. Also, ALB has limited suitability based on water clarity, turbidity, water depth, atmospheric weather conditions and the size of objects that require detection (Cunningham et al. [3]). Vessel deployed techniques rely upon echosounder (sonar) technology for penetration of the water surface and are thus much less susceptible to these challenges (USACE [4]).

The recent addition of mobile laser scanning (LiDAR) from the same vessel platform offers the significant advantage of extending the data set above the water line. This can play a valuable role by making a nearly continuous data set to the top of the embankment. This also reduces the importance of performing data collection only during yearly high water levels for the water course. An additional benefit is gained in the ability to survey locations where physical access with GPS or total station prism targets is difficult or dangerous.

The principle limitation of this platform integration is occlusion of principally the laser survey data (but in some cases also the bathymetry data) caused by occlusion of features by line-of-sight obstructions. Both technologies survey from "line-of-sight" ranging using amplitude threshold detection of light and sound waves respectively (USACE $[4,5])$. The ranging cannot pass through 


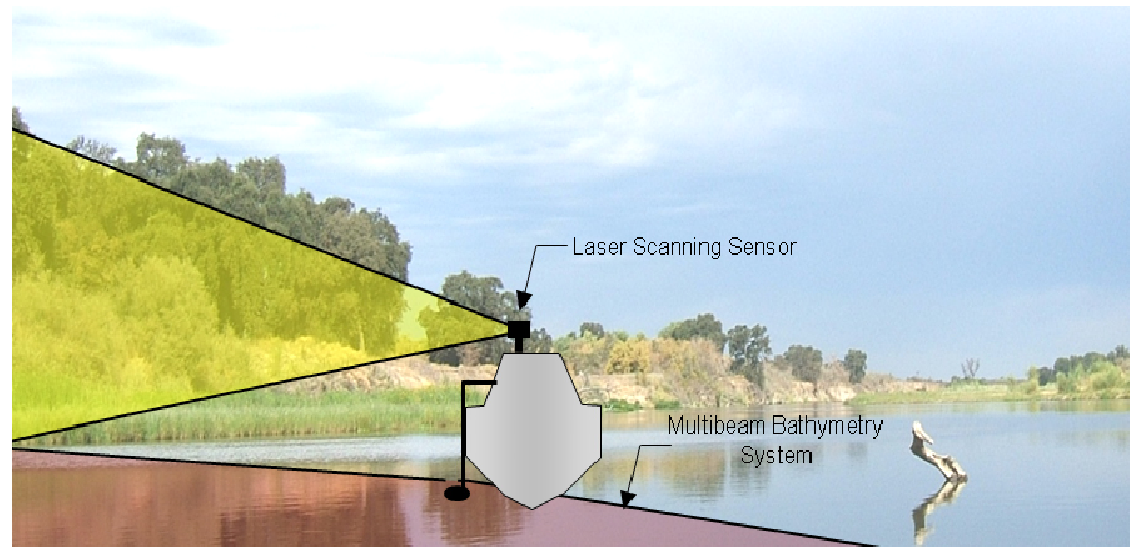

Figure 1: Conceptual diagram of integrated mobile laser sensor and multibeam bathymetry system.

obstructing objects. Although the very high density of laser scanners does typically allow for sufficient density to "see through" trees, this is actually sufficient point density to find paths through the foliage to the ground surface behind the vegetation and not light waves passing through the vegetative matter. In the cases of buildings, jetties, wharves, undulating topography, etc., the sensors are unable to record observations beyond the obstruction creating a void in the data. Addressing this challenge can be sometimes be done by utilizing the mobile scanner from a ground-based platform such as an ATV, UTV or truck. Additionally, the vessel-based data can be supplemented with data collected by static laser scanning, GPS, conventional or aerial survey methods, which is discussed later in this paper.

Point classification techniques that have been developed largely from aerial LiDAR workflows can be used for removal of vegetation features from point clouds which allow for creation of a bare earth surface, which is generally a prerequisite for creating a digital elevation model (DEM). DEM's are the precursor for many commercial topographic, engineering and modelling/visualization applications.

\section{Modelling}

Hydraulic modelling of riverine systems for characterization of levees and potential flood risks is one of the key applications for this technology (Mitchell and Chowdhury [6]). Additional modelling of landslides, debris flow, sediment transport, hydrostatic pressure, hydroelectric potential are possible by the high level of resolution and accuracy available from data sets of this nature as the technology matures. 


\section{River systems}

Collection of river bathymetry has commonly been done by cross sections at specified intervals through water courses (USACE [7]). This method has been the data source for most one dimensional hydraulic models. Although in many cases, this type of modelling has proved sufficient, it has inherent limitations.

Principally, finite difference models do not allow for varied water levels to be modelled in the river channel. They also require a fixed cell size for the grid. Using finite element modelling offers the flexibility to use a non-uniform mesh which can be designed to have higher density in complex areas. This allows the creation of an efficient detailed model (Marks and Bates [8]).
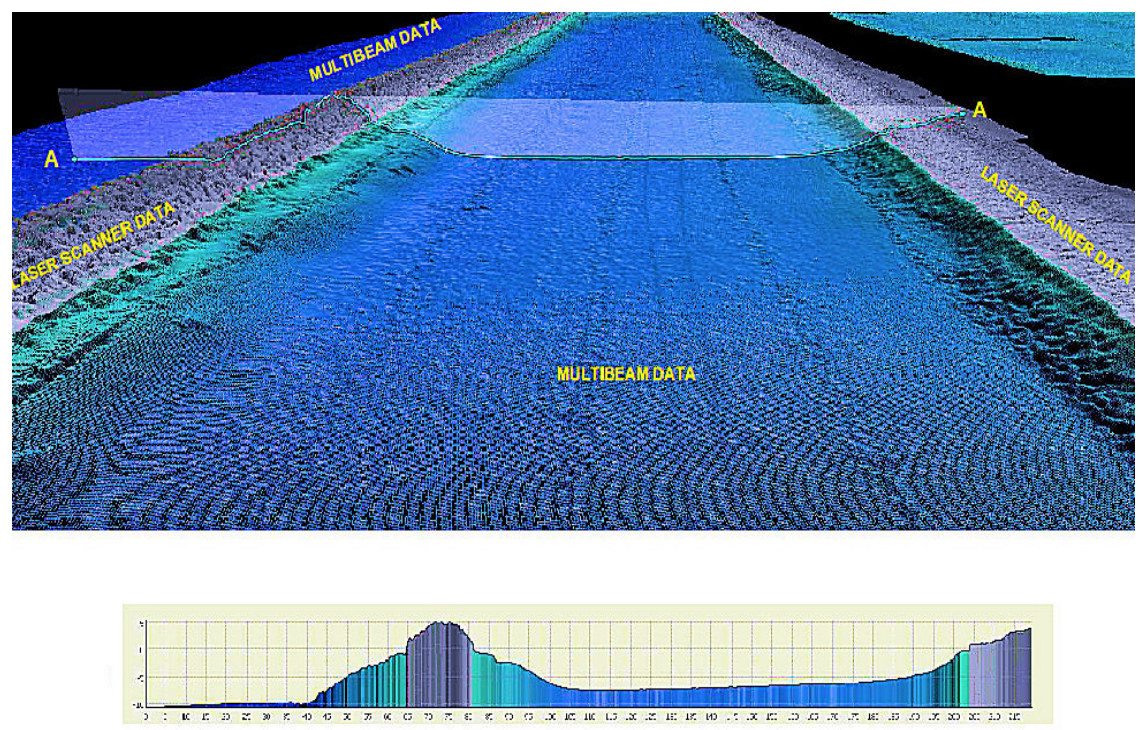

SECTION A-A'

Figure 2: Multibeam and laser scanning data provide an integrated data set that can be the source for cross-sections at a nearly infinite interval and bearing.

Finite element modelling also allows modelling of localized effects such as:

- Dead zones

- Shallow flow zones

- Flow diversions

- Distribution of depth-averaged velocities across the water course

- Water velocity near levees/embankment

- Inclusion of infrastructure features during modelling 


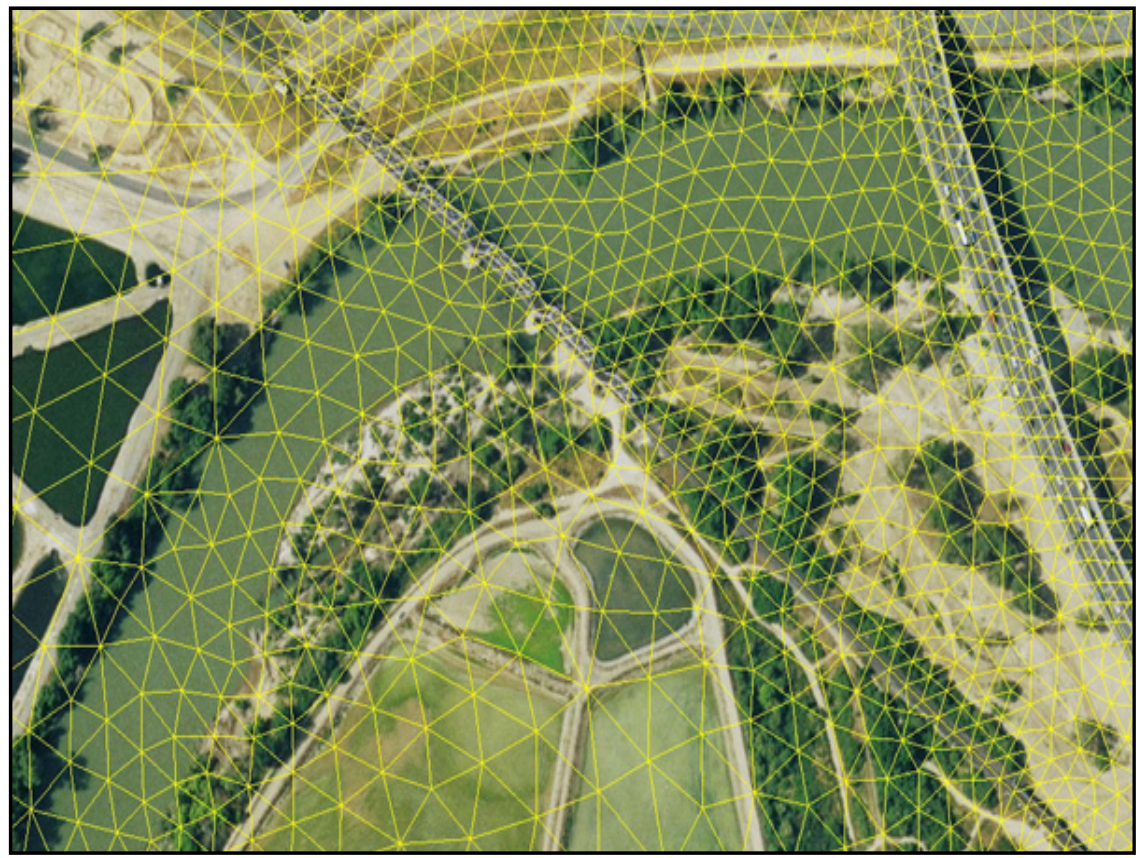

Figure 3: Finite element modelling allows for non-uniform triangular cells allowing for variable densification. (Image courtesy of Wood Rodgers, Inc.).

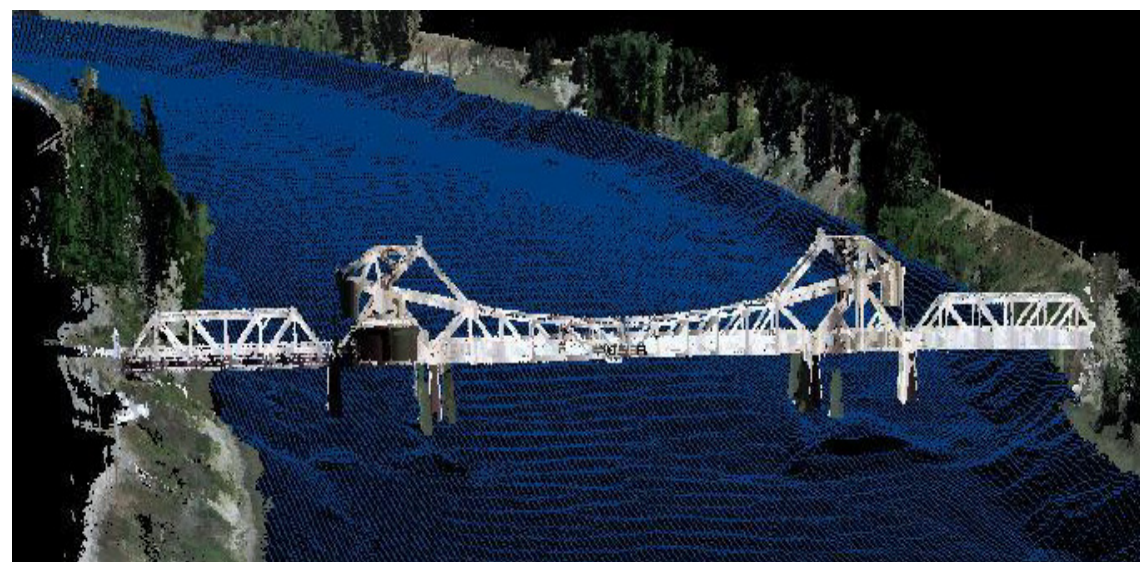

Figure 4: Consideration of bridge structure possible in hydraulic model.

Taking advantage of these additional features requires three dimensional topography of the river bottom to populate the elevation value of the nodes. However, even with multibeam bathymetry data, topography of the river channel above the water level during the time of survey requires additional collection. 
Incorporation of a mobile laser scanner compliments the multibeam sonar data providing coverage of the terrain on both sides of the water line.

The inclusion of topographic and infrastructure features (such as bridges) above the waterline offer a significant improvement in their inclusion in the hydraulic model. Similarly, vegetation has been incorporated into twodimensional hydraulic models that incorporate friction (Cobby et al. [9]).

\section{Reservoirs}

Water reservoirs impounded by dam structures typically accumulate river sediment trapped upstream. This accumulation will reduce the reservoir capacity over time as well as potentially impact dam head pressure. For hydroelectric facilities, the sediment can impact dam operations (Palmieri et al. [10]).

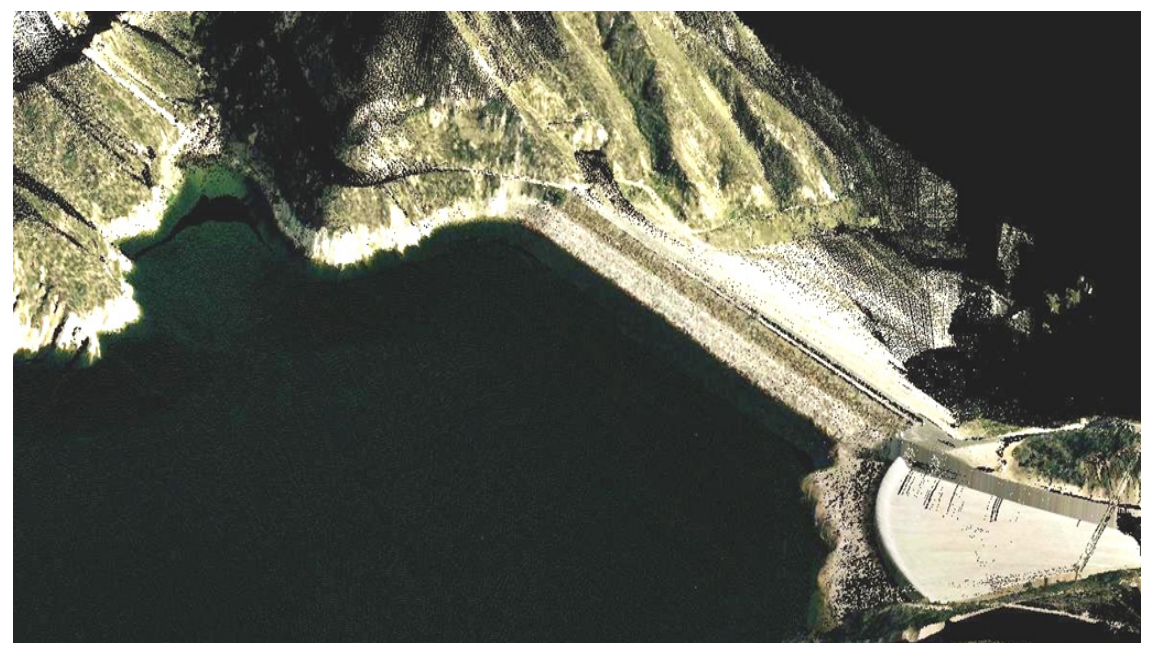

Figure 5: Mobile bathymetry/laser scanning survey of dam and reservoir.

Reservoirs impounded by dams are often in areas of complex geology. Natural basins can frequently be in mountainous areas, which can be areas prone to landslides. Forensic evidence of previous landslides and/or the presence of head scarp fissures are of critical importance for characterizing the geological conditions of a site and assessing risks to the infrastructure (Christenson and Ashland [11]). Integrated mobile laser scanning and bathymetry sensors can play a valuable role in identifying landslide evidence. In some cases, landslide debris may be located below the water line, making it very difficult to identify from a surficial inspection. Surficial movement of the terrain can be slow moving and hard to detect (Jaboyedoff et al. [12]). Characterization and modeling of rock outcrops can also be done with this technology (Bellian et al. [13]). Periodic laser scanning can be used to monitor changes over time. Some slide features such as fissures and head scarp can also be hidden by vegetation and not easily located using aerial photography nor accessed easily on foot. Integrating ground 
based laser scanning with aerial LiDAR surveying, can play a vital role in locating and monitoring features of this type.

\section{Virtual inspection}

Production of surveying data for conventional applications is the typical application of this hybrid technology. However, the sheer density of data collected in this manner and the high level of detail available in the data point cloud allows the creation of 3D models either in point cloud or a rendered format. Both have different pros and cons but both provide the ability to visualize the site in a way that cannot be reproduced on the ground.

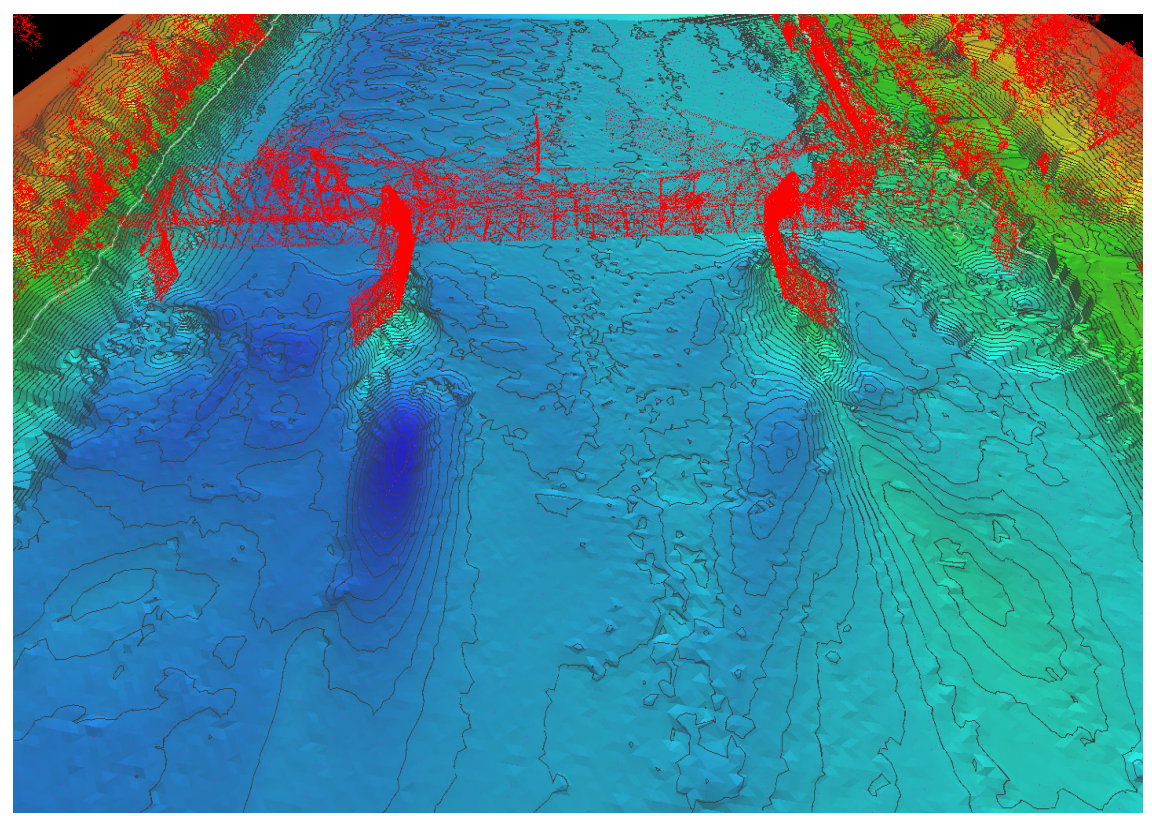

Figure 6: Analysis of data reveals sediment scour at bridge piers.

Conducting a virtual inspection using the data allows engineers to have an entirely different and measurable perspective on the site that can provide new insight into the geomorphology, topography and the planar geometry - all of which can be used in evaluation of the site for compliance with safe operation of the infrastructure. Sediment transport can also be studied including inspection of infrastructure features for risks associated with scour (Huizinga [14]).

Other opportunities lay in the ability to consider forensic evidence of geologic activity. Identification of head scarps, karst terrain or land slide debris hidden from unaided view as well as monitoring surficial movement over time are all valuable applications for this technology (Jaboyedoff et al. [12] and Schultz [15]). 


\section{Integration with other mapping data sets}

Although this technology set can play an important role for infrastructure characterization and study, there is a limitation imposed on site studies when the viewing aspect of the site is limited to only one perspective. Significant benefits can be realized by integration of the bathymetry and mobile laser scanning data products with data collected by other techniques - especially aerial sensor platforms. From panchromatic satellite imagery to hyperspectral aerial photogrammetry and/or aerial LiDAR topographic mapping, data collected from aerial platforms can be exceptionally valuable in assessing the site beyond the perspective available from a ground-based mobile platform. Key among these benefits is the ability to see beyond the direct line of site perspective. Features such as wharves, buildings, hills, etc. that block direct line of sight of the instruments prevent inclusion of features that are occluded during ground based data collection. Inclusion of aerial platforms offers the advantage of ensuring complete coverage of these occluded areas. The most important challenge when merging these data sets is the (typically) lower accuracy of aerial platform data caused largely by the range amplified errors that can be quite significant for high-altitude airborne sensor platforms (Baltsavias [16]).

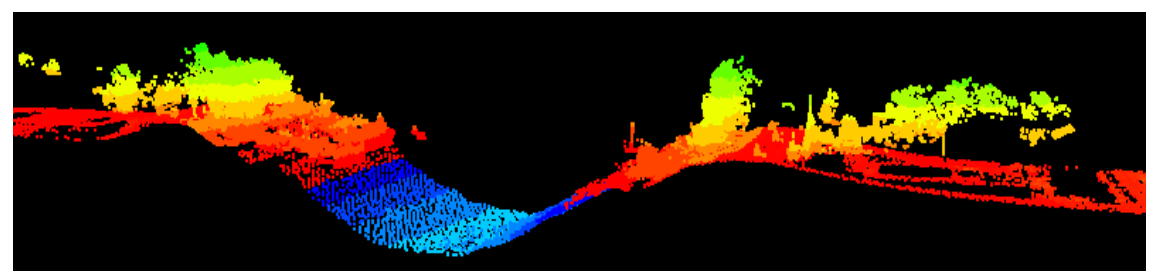

Figure 7: Integration of vessel based mobile survey data with aerial LiDAR data.

\section{Conclusion}

Vessel/ground based mobile mapping using bathymetry for underwater surveying and mobile laser scanning for above water topographic mapping offers a new and unique methodology for producing high resolution and high accuracy data sets that can offer significant improvement in mapping, modelling and virtual inspection of water retention infrastructure that have previously not been readily achieved. Utilization of sonar based multibeam bathymetry allows surveys of even of turbid, murky water that airborne LiDAR (laser) bathymetry sensors cannot perform. Wide-swath multibeam technology improves efficiency of collection, even in shallow waters and can often be "steered" to collect data below overhanging infrastructure like jetties or vessel berths.

The principle limitation of the technology is in the perspective of the topographic (laser) survey from the vessel but by supplementing with data from 
an aerial platform (including LiDAR, photogrammetry and/or satellite imagery), this challenge can be overcome.

Vessel based mobile mapping can provide a cost-effective, highly detailed and accurate method for mapping many water retention infrastructure applications.

\section{References}

[1] Axelsson, R. and Alfredsson, M. Capacity and capability for hydrographic missions, Proc. U.S. Hydrographic Conference, Mobile, AL, (paper 9-4 on CD), 9 pp., April 26-29, 1999.

[2] Banic, J. R., and A. G. Cunningham, Airborne laser bathymetry: A tool for the next millennium, EEZ Technology, 3, pp. 75-80, 1998.

[3] Cunningham, A.G., Lillycrop, W.J., Guenther, G.C., and Brooks, M.W. Shallow water laser bathymetry: accomplishments and applications, Proc. Oceanology International: The Global Ocean, Brighton, England, Vol. 3, pp. 277-288, 1998.

[4] U.S. Army Corps of Engineers (USACE), EM 1110-2-1003 Change 1 Engineering and Design - Hydrographic Surveying, Chapter 11. Department of the Army, 2004.

[5] U.S. Army Corps of Engineers (USACE), EM 1110-1-1005 Engineering and Design - Control and Topographic Surveying, Chapter 10. Department of the Army, 2007.

[6] Mitchell, T. and Chowdhury, S. "Above and Below the Waterline: Utilizing Mobile Laser Scanning and Multi-beam Bathymetry to Model the Sacramento River", Proc. of the International LiDAR Mapping Forum, New Orleans, LA, pp. 7, 2011.

[7] U.S. Army Corps of Engineers (USACE), EM 1110-2-1003 Civil Works Applications, Chapter 2. Department of the Army, 2002.

[8] Marks, K. and Bates, P. Integration of high-resolution topographic models with floodplain flow models. Hydrological Processes 14, pp. 2109-2122, 2000.

[9] Cobby, D. M., Mason, D. C., Horritt, M. S. and Bates, P. D., Twodimensional hydraulic flood modelling using a finite-element mesh decomposed according to vegetation and topographic features derived from airborne scanning laser altimetry. Hydrological Processes, 17, pp. 19792000, 2003.

[10] Palmieri A, Shah F, and Dinar A. 2001. Economics of reservoir sedimentation and sustainable management of dams. Journal of Environmental Management 61, pp. 149-63.

[11] Christenson, G.E., and Ashland, F.X., Assessing the stability of landslides overview of lessons learned from historical landslides in Utah, Proceedings for the 16 40th Symposium on Engineering Geology and Geotechnical Engineering, Logan, Utah State University, 17 p., 2006. 
[12] Jaboyedoff, M., Oppikofer, T., Abellán, Derron, M., Loye, A., Metzger, R. and Pedrazzini, A. Use of LiDAR in landslide investigations: a review, Natural Hazards, DOI 10.1007/s11069-010-9634-2, 2010

[13] Bellian, J. A., Kerans and C., Jennette, D. C., Digital Outcrop Models: Applications of Terrestrial Scanning Lidar Technology in Stratigraphic Modeling, Journal of Sedimentary Research, March; 75, pp. 166-176., 2005

[14] Huizinga, R.J., 2010, Bathymetric surveys at highway bridges crossing the Missouri River in Kansas City, Missouri, using a multibeam echo sounder, U.S. Geological Survey Scientific Investigations Report 5207, 61 p, 2010

[15] Schultz, W. H. (2007). Landslide susceptibility revealed by LIDAR imagery and historical records, Seattle, Washington Engineering Geology 89, Issues 1-2, pp. 67-87, 2007

[16] Baltsavias, E. P., Airborne laser scanning: basic relations and formulas. ISPRS Journal of Photogrammetry and Remote Sensing 54, 199-214. doi:10.1016/S0924-2716(99)00015-5, 1999 